\title{
A Systematic Review of MicroRNAs Involved in Cervical Cancer Progression
}

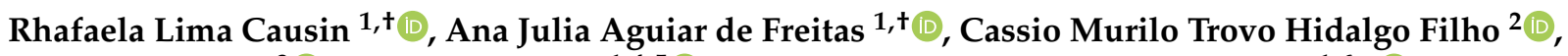 \\ Ricardo dos Reis ${ }^{3}\left(\mathbb{D}\right.$, Rui Manuel Reis ${ }^{1,4,5}$ and Márcia Maria Chiquitelli Marques $1,6, *(\mathbb{D})$ \\ 1 Molecular Oncology Research Center, Barretos Cancer Hospital, Teaching and Research Institute, \\ Barretos-SP 14784-400, Brazil; rhafaela-lima@hotmail.com (R.L.C.); aaguiardefreitas@gmail.com (A.J.A.d.F.); \\ ruireis.hcb@gmail.com (R.M.R.) \\ 2 Instituto do Câncer do Estado de São Paulo (ICESP), São Paulo-SP 01246-000, Brazil; muriloth@hotmail.com \\ 3 Gynecologic Oncology Department, Barretos Cancer Hospital, Barretos, São Paulo 14784-400, Brazil; \\ drricardoreis@gmail.com \\ 4 Life and Health Sciences Research Institute (ICVS), Medical School, University of Minho, \\ 4704-553 Braga, Portugal \\ 5 ICVS/3B's-PT Government Associate Laboratory, 4806-909 Braga/Guimarães, Portugal \\ 6 Barretos School of Health Sciences, Dr. Paulo Prata-FACISB, Barretos, São Paulo 14785-002, Brazil \\ * Correspondence: mmcmsilveira@gmail.com; Tel.: +55-17-3321-6600 (ext. 7057) \\ + These authors contributed equally to this work and share first authorship.
}

Citation: Causin, R.L.; Freitas, A.J.A.d.; Trovo Hidalgo Filho, C.M.; Reis, R.d.; Reis, R.M.; Marques, M.M.C. A Systematic Review of MicroRNAs Involved in Cervical Cancer Progression. Cells 2021, 10, 668. https://doi.org/10.3390/ cells10030668

Received: 13 February 2021

Accepted: 10 March 2021

Published: 17 March 2021

Publisher's Note: MDPI stays neutral with regard to jurisdictional claims in published maps and institutional affiliations.

Copyright: (c) 2021 by the authors. Licensee MDPI, Basel, Switzerland. This article is an open access article distributed under the terms and conditions of the Creative Commons Attribution (CC BY) license (https:// creativecommons.org/licenses/by/ $4.0 /)$.

\begin{abstract}
To obtain a better understanding on the role of microRNAs in the progression of cervical cancer, a systematic review was performed to analyze cervical cancer microRNA studies. We provide an overview of the studies investigating microRNA expression in relation to cervical cancer (CC) progression, highlighting their common outcomes and target gene interactions according to the regulatory pathways. To achieve this, we systematically searched through PubMed MEDLINE, EMBASE, and Google Scholar for all articles between April 2010 and April 2020, in accordance with the PICO acronym (participants, interventions, comparisons, outcomes). From 27 published reports, totaling 1721 cases and 1361 noncancerous control tissue samples, 26 differentially expressed microRNAs (DEmiRNAs) were identified in different International Federation of Gynecology and Obstetrics (FIGO) stages of cervical cancer development. It was identified that some of the dysregulated microRNAs were associated with specific stages of cervical cancer development. The results indicated that DEmiRNAs in different stages of cervical cancer were functionally involved in several key hallmarks of cancer, such as evading growth suppressors, enabling replicative immortality, activation of invasion and metastasis, resisting cell death, and sustained proliferative signaling. These dysregulated microRNAs could play an important role in cervical cancer's development. Some of the stage-specific microRNAs can also be used as biomarkers for cancer classification and monitoring the progression of cervical cancer.
\end{abstract}

Keywords: cervical cancer; microRNA; cervical cancer progression

\section{Introduction}

Cervical cancer (CC) is the most important human papillomavirus (HPV)-induced disease, being a major worldwide public health problem [1,2]. It corresponds to the fourth most common cancer among women in the world, with 569,847 new cases and 311,365 deaths registered annually [3]. There is an estimation that by 2030 the number of cervical cancer cases in the world will increase by around 50\% [4]. In Brazil, it is estimated that there were 16,370 new cases for each year of the 2018-2019 biennium, with an estimated risk of 15.43 cases for every 100,000 women [5].

Cervical cancer morbidity and mortality have declined in the last 40 years in many countries, mainly due to the effectiveness of the widespread implementation of prevention programs [6]. Effective screening programs have been introduced in many industrialized 
countries. However, in low and middle-income countries (LMICs), "Pap smear" programs have mainly been limited to offering the test to women present in primary health care centers and other health clinics $[7,8]$. For this reason, the current prevention programs in these countries are not having a major impact in terms of decreasing mortality [9]. In addition, the survival rate in a late stage is approximately $15 \%[10,11]$. Therefore, the prognosis and 5-year survival rate of patients with advanced cervical cancer still remain poor. The standard treatment for patients diagnosed with locally advanced stages (LACC) consists of radiotherapy in combination with cisplatin-based chemotherapy [12,13]. However, approximately $50 \%$ of patients do not respond to standard treatment; therefore, these patients have a higher rate of recurrence and a lower survival rate in the first five years [14].

The fundamental step in the malignant transformation of cervical cells is the interaction between these cells and HPV $[15,16]$. This infection can originate pre-neoplastic lesions [17], known as cervical intraepithelial neoplasia (CIN) (Figure 1). Based on their association with cervical cancer and precursor lesions, HPVs can also be grouped into high-risk and low-risk HPV types. Low-risk HPV types are those that cause genital warts but are not carcinogenic, including types $6,11,42,43$, and 44 [16,18]. High-risk HPV types are considered carcinogenic, and include 16, 18, 31, 33, 34, 35, 39, 45, 51, 52, 56, 58, 59, 66, 68 , and $70[6,16]$.

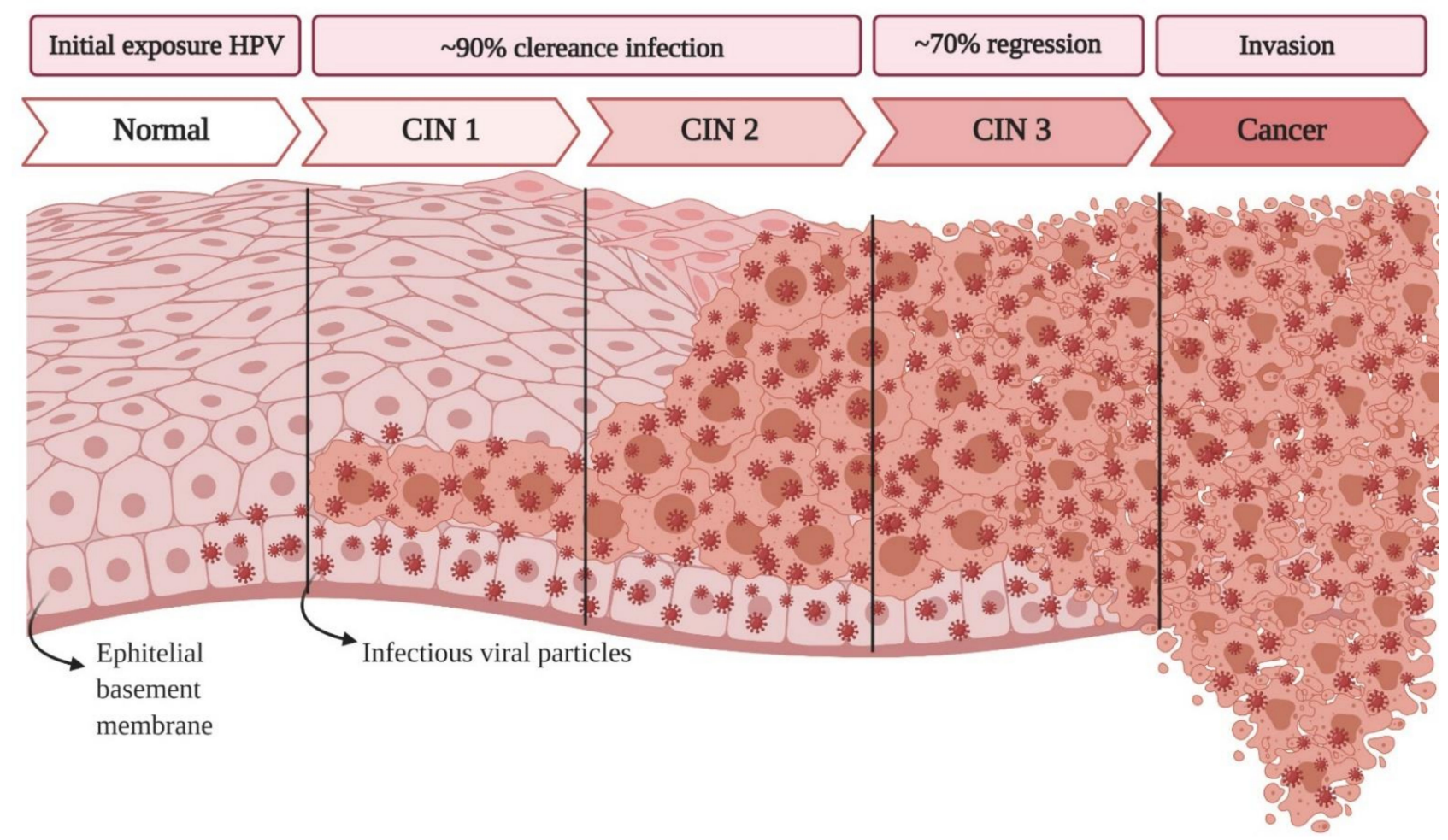

Figure 1. Classification of normal squamous epithelial cells and human papillomavirus (HPV) infections in normal precancerous lesions (cervical intraepithelial neoplasia grades 1, 2, and 3 "CIN 1, CIN 2, and CIN 3") and cervical cancer.

Wentzensen et al. [19] confirmed that HPV integration sites are randomly distributed over the whole genome, with a clear predilection for fragile sites. Thereby, this interaction is more frequent in chromosomal fragile sites (CFS); these regions of the chromosome are the most prone to genetic and epigenetic changes $[15,20]$. It is known that approximately $50 \%$ of microRNAs (miRNAs) are located in these fragile sites or in regions associated with cancer [21], and although the function of miRNAs as oncogenes or as tumor suppressors has already been well characterized [22], the mechanisms of action of miRNAs in the progression of CC have been studied only recently [23]. 
miRNAs are small non-coding RNAs (19 to 24 nucleotides) that regulate the expression of coding genes [24] with crucial roles in important biological processes, such as proliferation, cell growth, and apoptosis, among others $[25,26]$. The canonical pathway of biogenesis of miRNAs begins in the nucleus after the transcription of the miRNA by polymerase II-the synthesis of the primary miRNA (Pri-miRNA). Then, the Drosha enzyme linked to the DGCR8 cofactor cleaves the end of the poly AAA tail, giving rise to the precursor miRNA (Pre-miRNA), which is exported to the cytoplasm via exportin 5. In the cytoplasm, the Pre-miRNA clamp is cleaved by Dicer enzyme linked to the TRBP cofactor resulting in a duplex miRNA, at which point the RISC complex guides only one of the strands of mature miRNA to the target mRNA. Then, the interaction in the 3'UTR region occurs [27]. The result of the interaction between the mRNA and the miRNA can lead to inhibition of translation, in the event of imperfect pairing, or the degradation of the mRNA, which occurs in cases of perfect pairing between the miRNA and the mRNA [28] (Figure 2).

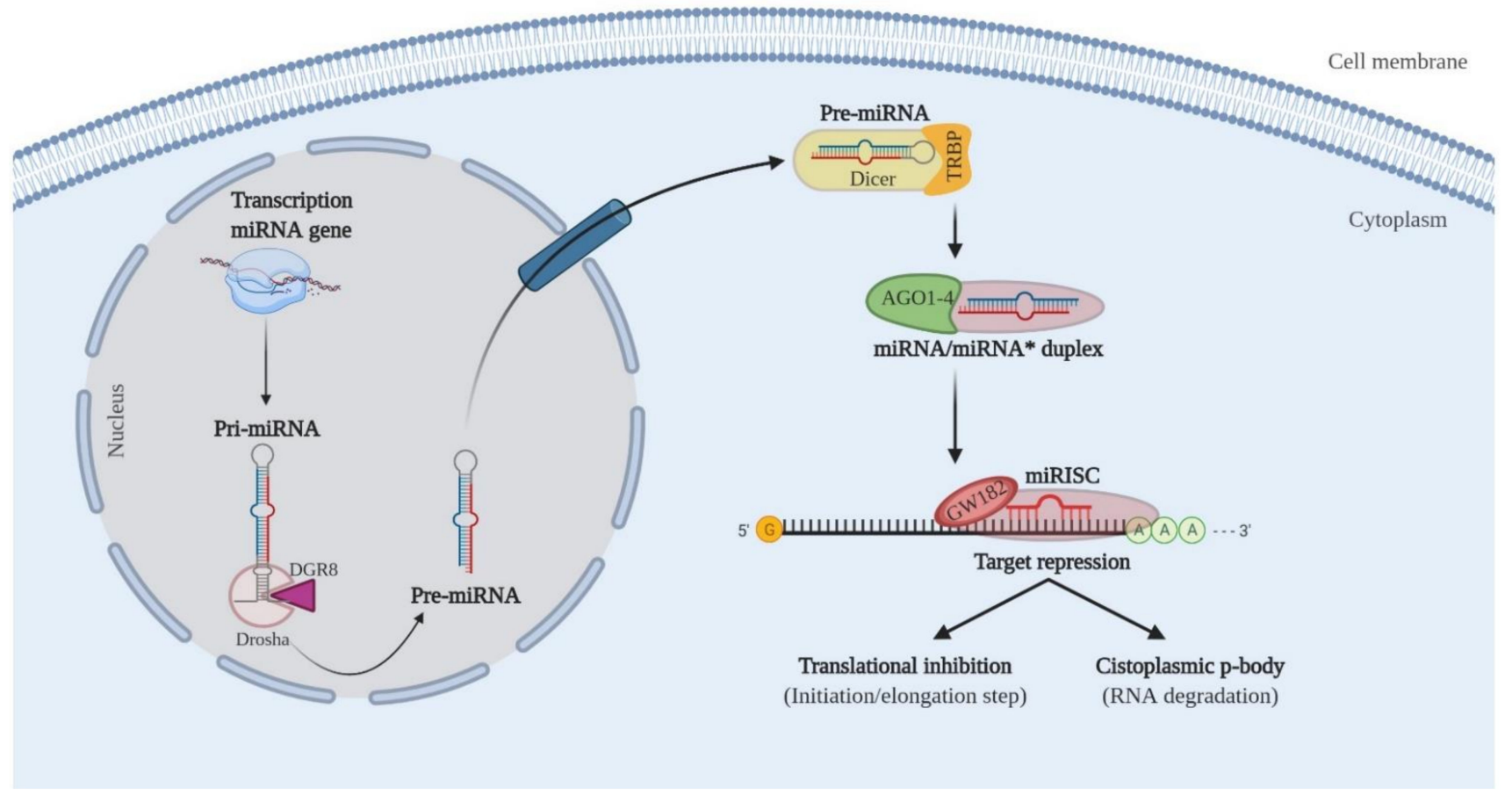

Figure 2. Biogenesis and modulation of microRNA activity.

Several factors are necessary for the development of $\mathrm{CC}$, including the interaction of viral and environmental factors and the host's immune capacity-steps that trigger tumor growth, invasion, and metastasis [29]. In addition, evidence about epigenetic regulatory mechanisms has steadily increased over the past two decades and has focused on the dysregulation of oncogenes and tumor suppressor genes as the main generator of the malignant phenotype [30]. In this sense, miRNAs play an important role as regulators of cellular processes, which involve apoptosis, cell cycle progression, metastases, invasion, and chemoradioresistance [31,32]. In an effort to understand the important roles of various miRNAs during cervical tumor genesis, many studies have been carried out to describe the real regulatory role of these molecules.

miRNAs can be subdivided into oncogenic miRNAs (oncomiRs) and tumor suppressor miRNAs (tsmiRs) [33]. For a future in personalized medicine for the treatment of CC, in which we can use miRNAs as possible therapeutic targets, we first need to understand the oncogenic or tumor suppressive role of miRNAs and how their regulation may affect $\mathrm{CC}$ development and progression. Blocking and downregulating oncomiRs may play an important role in the treatment of this tumor, while the overexpression of tsmiRs may provide anti-cancer therapeutic effects [22,34-36]. On the other hand, different tsmiRs 
have different mechanisms for suppressing CC [25,37]. Most of them, such as miR-1284, miR-573, miR-433, miR-424-5p, and miR-361-5p, can affect cellular proliferation, migration, and apoptosis. In the present review, we conducted an extensive search of the literature, which yielded information concerning 28 miRNAs associated with the progression of CC, as identified in 27 studies.

\section{Materials and Methods}

The Preferred Reporting Items for Systematic Reviews and Meta-Analyses (PRISMA) tool was used to ensure transparent reporting [38,39]. Both reviewers (RLC and AJAdF) performed an independent assessment of the quality of all included studies. Discrepancies were discussed and resolved by consensus.

\subsection{Search}

Potential articles for inclusion in the current study were searched for through PubMed MEDLINE, Embase, and Google Scholar databases between April 2010 and April 2020 using combinations of the keywords using Medical Subject Headings (MeSH) terms: "uterine cervix tumor" or "cervical intraepithelial neoplasia 2" or "cervical intraepithelial neoplasia 3," and "miRNA" or "microRNA," and "progression disease." The search was followed by checking references listed in the identified articles for potentially eligible original reports. After merging the results of the three searches, all records were individually screened by title and abstract by two authors (RLC and AJAdF). Discrepancies were discussed and resolved by consensus, resulting in either inclusion or exclusion for any full text.

\subsection{Inclusion and Exclusion Criteria}

We employed the PICO acronym (participants, interventions, comparisons, outcomes) for predetermined criteria for inclusion [38,40]; the criteria can be seen in Table 1. All miRNAs involved with cervical cancer studies were used in the present study if they met the following criteria: (i) original experimental report to analyze miRNA profile between human cancerous and noncancerous cervical tissues and/or CIN; (ii) articles published in the last 10 years; (iii) original articles published in either English or Spanish; and (iv) impact factor greater than or equal to 2 . The exclusion criteria were as follows: (i) articles entirely in silico; (ii) an article that belongs to a meta-analysis, thesis, series, abstract, comment, review, letter, or editorial; (iii) duplicate reports; (iv) studies that did not have control tissues and studies that did not use human samples; (v) articles that did not use cell lines and patients' samples; (vi) studies that did not to validate the interaction between the target gene and miRNA.

Table 1. Eligibility criteria in accordance with PICO (participants, interventions, comparisons, outcomes).

\begin{tabular}{cc}
\hline Domain & Inclusion Criteria \\
\hline Patients (P) & Patients with cervical cancer or cervical intraepithelial neoplasia grade 2/3 \\
Interventions (I) & Differentially expressed miRNAs \\
Comparators (C) & Non-neoplastic control tissue or cervical cancer FIGO stage I \\
Outcomes (O) & Differentially expressed miRNAs indicate a statistically significant difference in the overall survival of patients \\
\hline
\end{tabular}

\subsection{Data Extraction}

Data were extracted from all publications that met the inclusion criteria according to two independent reviewers using a standardized data extraction form. We extracted the following information for each eligible study; study design, year of publication, specimens (cell lines and patients sample type), number of patients, International Federation of Gynecology and Obstetrics (FIGO)stages, miRNA deregulated, target interaction, target interaction validation, hallmarks of cancer, and clinical outcome. In case data were unavailable in the manuscript or supplementary files, the articles were excluded. 


\section{Results}

Hereafter, we selected 113 studies for a full-text review, and 27 studies [41-67] were eventually identified as eligible and were included in the present study (Figure 3). All 27 articles included were observational and experimental studies, 11 of which were carried out with experiments on animals. Included patient numbers ranged from 21 to 147, and resulted in a total of 1785 patients (1721 CC cases and 1361 noncancerous control tissue cases).

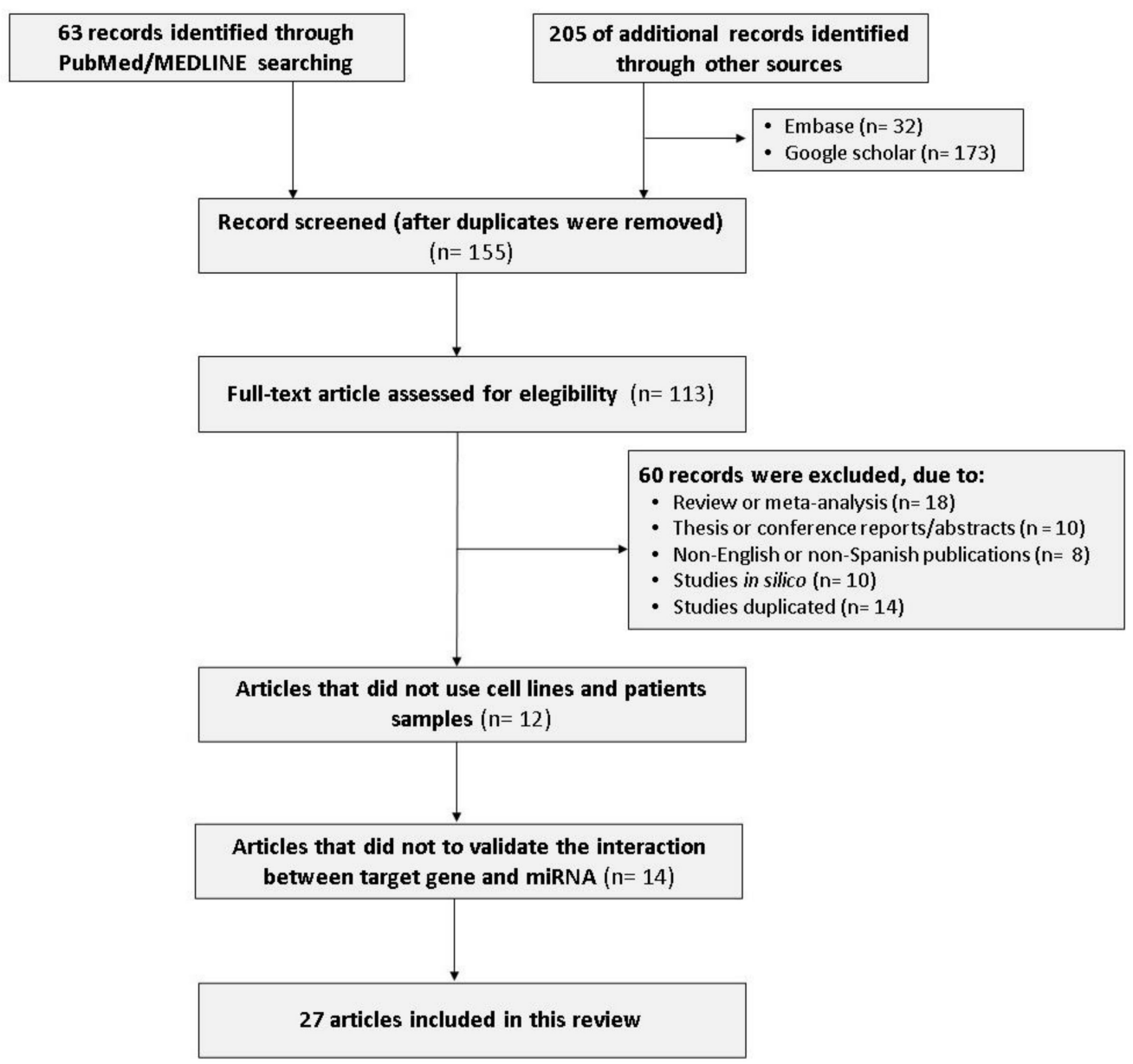

Figure 3. The flow chart of data identification and selection.

\subsection{Study Population}

All samples used in the included studies evaluated human tissues; the vast majority of normal tissues consisted of normal tissues adjacent to the tumor; three studies included healthy tissues, and the other three used CIN samples. All studies included patients according to FIGO stages. We also removed circulating miRNA studies with serum or plasma samples due to the lack of a sufficient number of independent studies. The main characteristics extracted from various datasets are summarized in Table 2, which include the number of patients investigated, the measurement platform, the pathological description of samples, and the identities of differentially expressed miRNAs (DEmiRNAs). 
Table 2. Characteristics of studies included in the current review.

\begin{tabular}{|c|c|c|c|c|c|c|}
\hline Author, Year & Country & Cell Lines & Sample & $\mathbf{N}$ & $\begin{array}{l}\text { Non-Neoplastic } \\
\text { Control Tissue (n) }\end{array}$ & $\begin{array}{l}\text { Cervical Cancer } \\
\text { Samples } \\
\text { FIGO Stage (n) }\end{array}$ \\
\hline Chen and Li, 2018 [41] & China & MS751, HeLa, SiHa e C33 A and ECS & Tissue & 82 & NAT (82) & $\begin{array}{l}\text { I (28) } \\
\text { II (54) }\end{array}$ \\
\hline Chen et al., 2018 [42] & China & $\begin{array}{c}\text { SiHa, HeLa, C-33A, Me180, Ms751 and } \\
\text { Ect1/E6E7 }\end{array}$ & Frozen Tissue & 45 & NAT (45) & $\begin{array}{l}\text { I-II (26) } \\
\text { III-IV (19) }\end{array}$ \\
\hline $\begin{array}{l}\text { Ding and Zhang, } \\
2019 \text { [43] }\end{array}$ & China & HeLa, SiHa, C-33A, SW75 and HcerEpic & FrozenTissue & 46 & NAT (46) & $\begin{array}{l}\text { I (31) } \\
\text { II (15) }\end{array}$ \\
\hline Dong et al., 2018 [44] & China & C-33A, ME-180, CaSki, HeLa, SiHa and NC104 & Tissue & 81 & NAT (81) & $\begin{array}{l}\text { I (46) } \\
\text { II (35) }\end{array}$ \\
\hline Gao et al., 2019 [45] & China & $\begin{array}{c}\text { SiHa, HeLa, C-33A, Me180 and Ms751 } \\
\text { and Ect1/E6E7 }\end{array}$ & Frozen Tissue & 66 & NAT (66) & $\begin{array}{l}\text { I-II (29) } \\
\text { III-IV (37) }\end{array}$ \\
\hline Hu et al., 2019 [46] & China & HeLa, SiHa, C-33A and Ect1-E6E7 & Frozen Tissue & 33 & NAT (33) & $\begin{array}{l}\text { I-II (13) } \\
\text { III-IV (20) }\end{array}$ \\
\hline Liang et al., 2019 [47] & China & $\begin{array}{c}\text { CaSki, SW756, SiHa, C-33A, HeLa, ME-180 and } \\
\text { Ect1-E6E7 }\end{array}$ & Frozen Tissue & 65 & NAT (65) & $\begin{array}{l}\text { I-II (37) } \\
\text { III-IV (28) }\end{array}$ \\
\hline Liao et al., 2018 [48] & China & SiHa, HeLa, C-33A, CaSki and Ect1/E6E7 & Frozen Tissue & 49 & NAT (49) & $\begin{array}{l}\text { I-II (23) } \\
\text { III-IV (26) }\end{array}$ \\
\hline Ou et al., 2019 [49] & China & C-33A, $\mathrm{SiHa}$, and CaSk & Tissue & 81 & NAT (81) & $\begin{array}{l}\text { Ib-IIa (37) } \\
\text { IIb-IIIa (44) }\end{array}$ \\
\hline Shan et al., 2019 [50] & China & HeLa, SiHa, CaSki, C-33A and Ect1/E6E7 & Frozen Tissue & 45 & NAT (45) & $\begin{array}{l}\text { I-II (17) } \\
\text { III-IV (28) }\end{array}$ \\
\hline Shao et al., 2019 [51] & China & $\begin{array}{l}\text { C-33A, MS751, SiHa, HeLa, ME-180, CaSki } \\
\text { and NC104 }\end{array}$ & Tissue & 37 & NAT (37) & $\begin{array}{l}\text { I-II (19) } \\
\text { III-IV (18) }\end{array}$ \\
\hline Wang et al., 2020 [52] & China & HeLa, SiHa, C-33A, SW756 and HcerEpic & Tissue & 55 & NAT (55) & $\begin{array}{l}\text { I (31) } \\
\text { II (24) }\end{array}$ \\
\hline Xu et al., 2018 [53] & China & $\begin{array}{c}\text { HeLa, CaSki, SiHa, ME-180, MS-751, C-33 A, } \\
\text { Ect1/E6E7 and HcerEpic }\end{array}$ & Frozen Tissue & 70 & NAT (70) & $\begin{array}{l}\text { I-II (36) } \\
\text { III-IV (34) }\end{array}$ \\
\hline Xu et al., 2019 [54] & China & C-33A, SiHa, ME-180, HeLa, CaSki and NC104 & Tissue & 92 & NAT (92) & $\begin{array}{l}\text { Ib-IIa (46) } \\
\text { IIb-IIIa (46) } \\
\text { I (56) }\end{array}$ \\
\hline Zhang et al., 2018 [55] & China & $\mathrm{HeLa}$ & Tissue & 100 & NAT (100) & $\begin{array}{l}\text { II (32) } \\
\text { III (8) } \\
\text { IV (4) }\end{array}$ \\
\hline Hu et al., 2019 [56] & China & SiHa, CaSki, HeLa, C4-1, and NC104 & Frozen Tissue & 21 & NAT (21) & $\begin{array}{l}\text { I (34) } \\
\text { II (27) }\end{array}$ \\
\hline Zhu et al., 2018 [57] & China & HeLa, CaSki, C4-1, SiHa, and GH329 & Tissue & 52 & NAT (52) & $\begin{array}{l}\text { I-II (30) } \\
\text { III-IV (23) }\end{array}$ \\
\hline Liang et al., 2017 [58] & China & HeLa, C-33A, SiHa, CaSki, and Hct1/E6E7 & Frozen Tissue & 65 & NAT (65) & $\begin{array}{l}\text { I-II (24) } \\
\text { II-IV (41) }\end{array}$ \\
\hline Dong et al., 2017 [59] & Japan & $\mathrm{HeLa}, \mathrm{SiHa}$ and $\mathrm{H} 8$ & Frozen Tissue & 58 & NAT (58) & $\begin{array}{l}\text { I-II (38) } \\
\text { III-IV (20) } \\
\text { I (28) }\end{array}$ \\
\hline Hu et al., 2016 [60] & China & HeLa, SiHa, C-33A and H8 & Frozen Tissue & 57 & NAT (57) & $\begin{array}{l}\text { II (14) } \\
\text { III (9) } \\
\text { IV (3) }\end{array}$ \\
\hline Huang et al., 2016 [61] & China & HeLa, SiHa, CaSki, C-33A, and HaCaT & Frozen Tissue & 40 & NAT (40) & I-II (40) \\
\hline Huang et al, 2016 [62] & China & SiHa and CaSki & Frozen Tissue & 190 & HT (64) & $\begin{array}{l}\text { I (86) } \\
\text { II }(40)\end{array}$ \\
\hline Su et al., 2017 [63] & China & $\mathrm{HeLa}$ & Frozen Tissue & 74 & & $\begin{array}{l}\text { I-II (39) } \\
\text { III-IV (35) }\end{array}$ \\
\hline Zhou et al., 2016 [64] & China & HeLa, SiHa, CaSki, ME-180, C-33A and HaCaT & Tissue & 50 & & $\begin{array}{l}\text { IB (27) } \\
\text { IC-IV (23) }\end{array}$ \\
\hline Wang et al., 2014 [65] & China & HeLa, SiHa, CaSki, ME-180, C-33A and HaCaT & Tissue & 27 & & $\begin{array}{l}\text { I (20) } \\
\text { II (7) }\end{array}$ \\
\hline Xu et al., 2013 [66] & China & $\mathrm{SiHa}$ and $\mathrm{CaSki}$ & Frozen Tissue & 147 & & $\begin{array}{l}\text { I (108) } \\
\text { II (39) }\end{array}$ \\
\hline Xu et al., 2016 [67] & China & SiHa, CaSki, HEK293T and HaCaT & Frozen Tissue & 57 & NAT (57) & $\begin{array}{l}\text { I (35) } \\
\text { II (22) }\end{array}$ \\
\hline
\end{tabular}

NAT: normal tissue adjacent to the tumor. HT: healthy tissue.

\section{2. miRNAs Involved in Cervical Cancer Progression}

Interestingly, all DEmiRNAs was confirmed by qRT-PCR. We identified 26 miRNAs reflecting the progression of cervical cancer. There are 19 downregulated (miR-1284, miR-573, miR-433, miR-424-5p, miR-361-5p, miR-383-5p, miR-335-5p, miR-874, miR-132, miR-411, miR-337-3p, miR-3941, miR-545, miR-143, miR-107, miR-1, miR-139-3p, miR-195, and 2861) and seven upregulated (miR-96-5p, miR-199b-5p, miR-93, miR-200a, miR-224, miR-92a, and miR-31) miRNAs among different stages of cervical cancer compared to normal tissue. These data are summarized in Table 3. 
Table 3. Differential expression of microRNAs (miRNAs) and targets genes in cervical cancer (CC) samples and cell lines.

\begin{tabular}{|c|c|c|c|c|}
\hline miRNA & Target Interation & Target Prediction Tool & Target Validated & REF \\
\hline miR-1284 & HMGB1 & miRanda & Luciferase & [41] \\
\hline miR-573 & $\mathrm{E} 2 \mathrm{~F} 3$ & Targetscan & Luciferase & {$[42]$} \\
\hline miR-433 & circ-ATP8A2/EGFR & Targetscan & Luciferase & {$[43,58]$} \\
\hline miR-424-5p & SNHG12 & StarBase v2.0 & Luciferase & {$[44,66]$} \\
\hline miR-361-5p & SBF2-AS/FOXM1 & Previous studies $[68,69]$ & Luciferase & [45] \\
\hline $\operatorname{miR}-383-5 p$ & LINC01128/SFN & StarBase v2.0 & Luciferase & [46] \\
\hline miR-335-5p & DANCR/ROCK1 & DIANA-LncBase V.2; Targetscan Human 7.2 & Luciferase & [47] \\
\hline miR-874 & ETS1 & TargetScan7.1 and microRNA.org & Luciferase & \\
\hline miR-132 & KDM2A/RDX & PicTar algorithm & Luciferase & [49] \\
\hline miR-411 & STAT3 & TargetScan and miRanda & Luciferase & [50] \\
\hline miR-96-5p & STXBP5-AS1/PTEN & TargetScan and miRanda & Luciferase & [51] \\
\hline miR-337-3p & hsa_circ_0001038, CNNM3/MACC1 & Circular RNA Interactome and TargetScan & Luciferase & {$[52]$} \\
\hline miR-199b-5p & KLK10 & TargetScan and miRanda & Luciferase & [53] \\
\hline miR-3941 & lncRNA RP11-552M11.4/ATF1 & DIANA tool LncBase v.2 and TargetScan & Luciferase & [54] \\
\hline miR-93 & CDKN1A & Previous studies [70-74] & Luciferase [70-73] & [55] \\
\hline miR-545 & circ_0067934/EIF3C & Circular RNA Interactome and TargetScan & Luciferase & [56] \\
\hline miR-200a & XIST/Fus & Starbase & Luciferase & [57] \\
\hline miR-143 & MSI-2/c-FOS & RNA-IP & Luciferase & [59] \\
\hline miR-107 & MSI-2/c-FOS & RNA-IP & Luciferase & [59] \\
\hline miR-1 & G6PD & RNA-IP & Luciferase & [60] \\
\hline miR-139-3p & NOB1 & TargetScan, miRanda, and Diana microT computational algorithms & RIP-Chip and Luciferase & [61] \\
\hline $\operatorname{miR}-224$ & RASSF8 & TargetScan Human 7.0 & Luciferase & [62] \\
\hline miR-92a & p21 & TargetScan, PicTar and microbase & Luciferase & [63] \\
\hline miR-195 & SMAD3 & Previous study [75] & Luciferase [75] & [64] \\
\hline miR-31 & ARID1A & TargetScan, pictar, and miRanda & Luciferase & [65] \\
\hline miR-2861 & EGFR/ AKT2/CCND1 & TargetScan, pictar, miRanda and Microcosm Targets & Luciferase & [67] \\
\hline
\end{tabular}

Hanahan and Weinberg [76] described ten hallmarks of cancer, of which five have the most impact on miRNA regulation and CC progression in according with this search. In this review, we focus on the following: proliferation, enabling replicative immortality, activation of invasion and migration (metastasis), resisting cell death (apoptosis), and sustained proliferative signaling in CC. In fact, we identified different miRNAs involved in these processes and responsible for the CC progression (Figure 4). In this review, we summarized data from an extensive bibliographical investigation regarding miRNAs associated with clinical outcome by overall survival (OS) (Table 3).

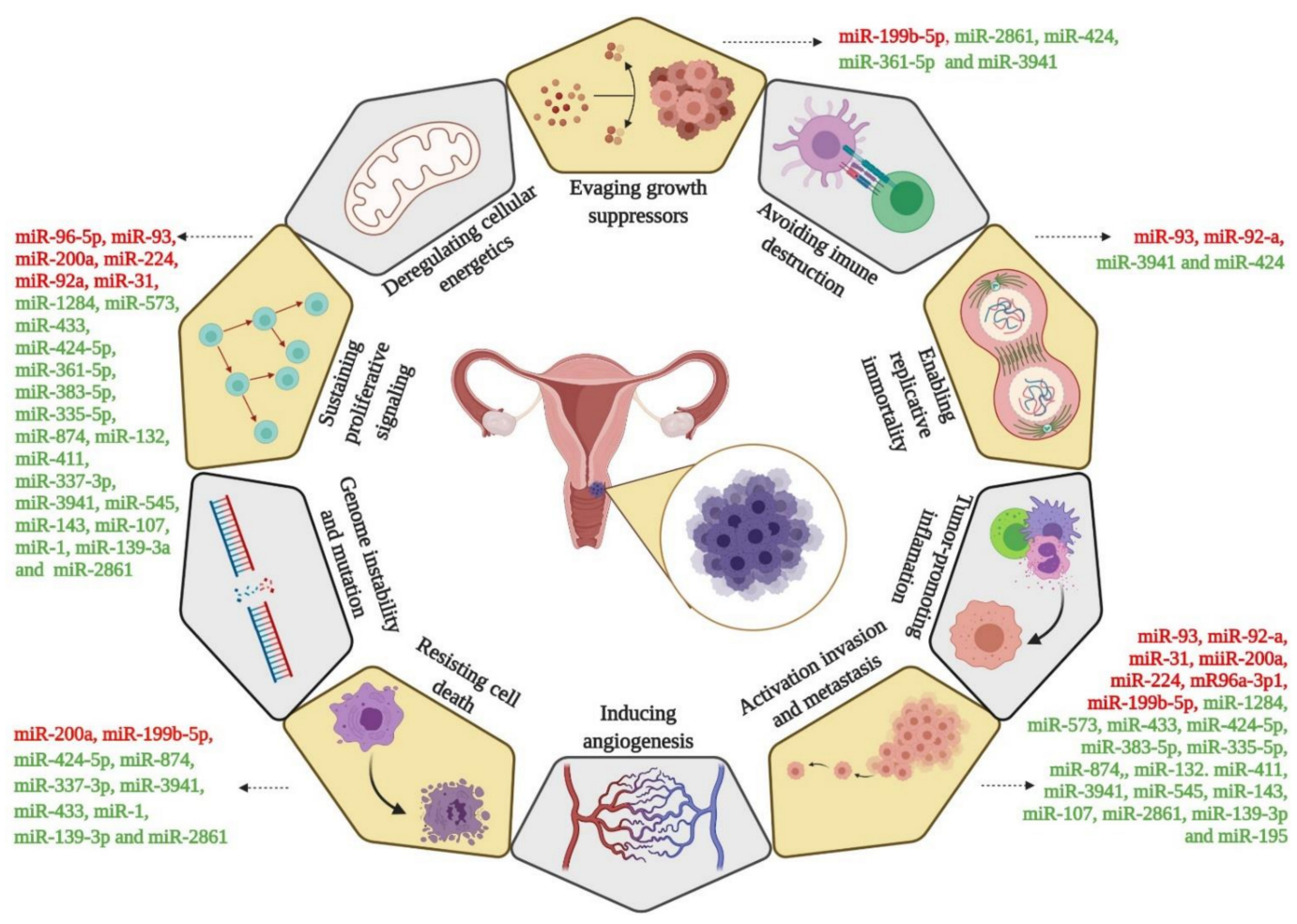

Figure 4. Different miRNAs affecting the hallmarks of cervical cancer. 


\subsection{Targets of miRNAs Involved in the Cervical Cancer Progression}

The conventional treatment for patients diagnosed with LACC is radiotherapy concomitant with cisplatin [12]. However, approximately $50 \%$ of LACC patients receiving conventional treatment exhibit recurrence [77] or poor prognosis in the first five years of disease [14]. Thus, resistance to therapy is a major obstacle for efficient cervical cancer treatment [78]. Recently, several miRNAs have been associated with the survival and prognosis of CC patients [79]. Consequently, the expression and regulation of their targets have become molecular markers with clinical relevance.

For instance, the expression profiles of 26 cancer-related miRNAs from $57 \mathrm{CC}$ tumor tissue were analyzed. Through prediction target tools, the authors identified the target interaction between DEmiRNAs and target genes. Finally, we associated this interaction of tsmiRs and oncomiRs with hallmarks of cancer (Figure 5), specifically, pathways related to CC progression. The physical interactions between miRNAs and target genes predicted by in silico tools were validated using luciferase assay; these data are summarized in Table 4.

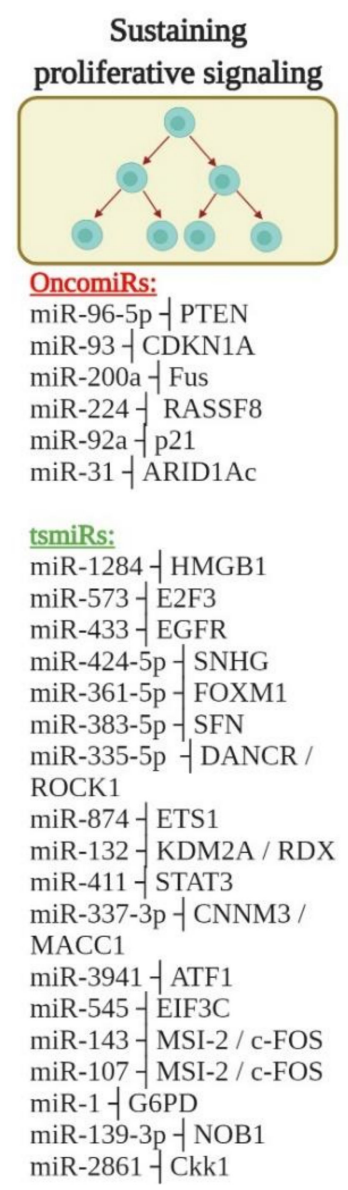

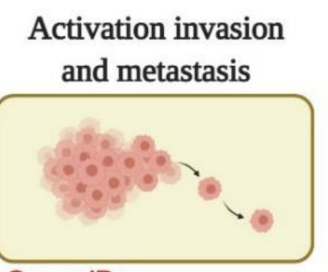

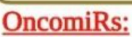

miR-96-5p - PTEN

miR-93 † CDKN1A

miR-200a - Fus

miR-224 - RASSF8

miR-92a-p21

miR-31 † ARID1A

miR-199b-5p - KLK10

tsmiRs:

miR-1284 † HMGB1

miR-573 - E2F3

miR-433 - EGFR

miR-424-5p - SNHG

miR-383-5p - SFN

miR-335-5p † DANCR /

ROCK1

miR-874 - ETS1

miR-132- KDM2A / RDX

miR-411 - STAT3

miR-3941 - ATF1

miR-545 - EIF3C

miR-143 - MSI-2 / c-FOS

miR-107 - MSI-2 / c-FOS

miR-2861 - Ckk1

miR-139-3p - NOB1

miR-195 - SMAD3

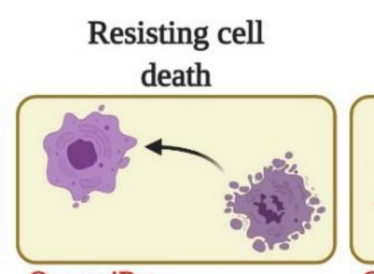

OncomiRs:

miR-200a - Fus

miR-199b-5p † KLK10

tsmiRs:

miR-424-5p $\dashv$ SNHG

miR-874 † ETS1

miR-337-3p - CNNM3 /

MACC1

miR-3941 † ATF1

miR-433 † EGFR

miR-1 † G6PD

miR-139-3p - NOB1

miR-2861 † Ckk1

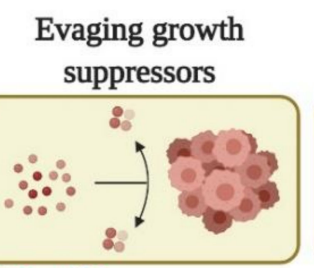

OncomiRs:

miR-199b-5p - KLK10

tsmiRs:

miR-424-5p - SNHG

miR-361-5p - FOXM1

miR-3941 - ATF1

miR-2861 - Ckk1
Enabling replicative immortality

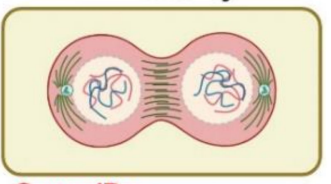

OncomiRs:

miR-93 † CDKN1A

miR-92a † p21

tsmiRs:

miR-424-5p - SNHG miR-3941 - ATF1

Figure 5. miRNAs involved in post-transcriptional regulatory interactions in cervical cancer. The oncogenic miRNAs (oncomiRs) and tumor suppressor miRNAs (tsmiRs) associated with various hallmark characteristics of cervical cancer are listed under the red and green subheadings, respectively. Each of these miRNAs can post-transcriptionally regulate a large number of genes involved in cervical cancer. The symbol $t$ indicates a negative regulating miRNA and target gene. 
Table 4. miRNAs involved in cervical cancer's clinical outcome.

\begin{tabular}{ccccc}
\hline miRNA & Status & Methodology & Outcome & REF \\
\hline miR-1284 & D & RT-qPCR & Poor prognosis & {$[41]$} \\
miR-573 & D & RT-qPCR & Poor prognosis & {$[42]$} \\
miR-433 & D & RT-qPCR & Poor prognosis & {$[43,58]$} \\
miR-424-5p & D & RT-qPCR & Poor prognosis & {$[44,66]$} \\
miR-361-5p & D & RT-qPCR & Poor prognosis & {$[45]$} \\
miR-383-5p & D & RT-qPCR & Poor prognosis & {$[46]$} \\
miR-335-5p & D & RT-qPCR & Poor prognosis & {$[47]$} \\
miR-874 & D & RT-qPCR & Poor prognosis & \\
miR-132 & D & RT-qPCR & Poor prognosis & {$[49]$} \\
miR-411 & D & RT-qPCR & Poor prognosis & {$[50]$} \\
miR-96-5p & U & RT-qPCR & Poor prognosis & {$[51]$} \\
miR-337-3p & D & RT-qPCR & Poor prognosis & {$[52]$} \\
miR-199b-5p & U & RT-qPCR & Poor prognosis & {$[53]$} \\
miR-3941 & D & RT-qPCR & Poor prognosis & {$[54]$} \\
miR-93 & U & RT-qPCR & Poor prognosis & {$[55]$} \\
miR-545 & D & RT-qPCR & Poor prognosis & {$[56]$} \\
miR-200a & U & RT-qPCR & Poor prognosis & {$[57]$} \\
miR-143 & D & RT-qPCR & Poor prognosis & {$[59]$} \\
miR-107 & D & RT-qPCR & Poor prognosis & {$[59]$} \\
miR-1 & D & RT-qPCR & Poor prognosis & {$[60]$} \\
miR-139-3p & D & RT-qPCR & Poor prognosis & {$[61]$} \\
miR-224 & U & RT-qPCR & Poor prognosis & {$[62]$} \\
miR-92a & U & RT-qPCR & Poor prognosis & {$[63]$} \\
miR-195 & D & RT-qPCR & Poor prognosis & {$[64]$} \\
miR-31 & U & RT-qPCR & Poor prognosis & {$[65]$} \\
miR-2861 & D & Microarray and RT-qPCR & Poor prognosis & {$[67]$} \\
\hline Dis & & &
\end{tabular}

D: dowregulated. U: upregulated.

\section{Discussion}

In summary, the expression levels of several miRNAs were repeatedly found to be associated with progression towards CC by regulating target genes in different studies $[45-47,53,80]$. In this sense, many DEmiRNAs and target genes have been studied, the majority of which are associated with apoptosis, cell cycle control, migration, genetic instability, cell adhesion, and metastasis. In this study, we identified miRNAs responsible for regulating different genes that act in CC progression pathways.

Most of the dysregulated miRNAs were downregulated (miR-1284, miR-573, miR-433, miR-424-5p, miR-361-5p, miR-383-5p, miR-335-5p, miR-874, miR -132, miR-411, miR-3373p, miR-3941, miR-545, miR-143, miR-107, miR-1, miR-139-3p, miR-195, and miR-2861), and low expression of them was associated with a poor prognosis. Huang et al [61]. identified that miR-139-3p is capable of suppressing cell proliferation, migration, and invasion, and induces apoptosis by negative regulation of NOB1 in CC cells. These results suggest that miR-139-3p can act as a tumor suppressor, suppressing NOB1 expression in the progression of CC. Another study [66] suggested that miR-424 contributes to the progression of cervical cancer at least partly via upregulation of target gene Chk1 expression and phosphorylation of Chk1 protein. miR-424 might become a potential predictor for prognosis and a candidate target therapy for cervical cancer patients. In addition, a study [67] demonstrated that the interaction of the E6 oncoprotein could also cause a decrease in the expression of a tsmiR, by which HPV16 E6 is able to decrease the level of miR-2861 expression, resulting in the suppression of the EGFR/AKT2/CCND1 pathway in cervical cancer cells. In summary, a new regulatory network was found, employing HPV16 E6, miR-2861, and the EGFR/AKT2/CCND1 signaling pathway to syntonize proliferation, apoptosis, and invasion in cervical cancer cells. This understanding of the single molecular pathway, HPV16 E6/miR-2861/EGFR/AKT2/CCND1, may provide a new insight into exploring additional strategies for cervical cancer therapy in the future. 
On the other hand, our study identified seven upregulated miRNAs (miR-96-5p, miR-199b-5p, miR-93, miR-200a, miR-224, miR-92a, and miR-31), among which it was seen that such upregulated miR-93 was correlated with shorter overall survival than low expression of miR-93 $(\mathrm{P}<0.01)$. Patients with low expression levels of CDKN1A mRNA more often had shorter overall survival than those with high expression levels of CDKN1A mRNA $(\mathrm{P}<0.01)$ [55]. In addition, the survival rate of patients with upregulated miR-93 downregulated CDKN1A was the shortest $(\mathrm{P}<0.01)$. In another study [63], it was reported that miR-92a, which is upregulated in cervical cancer, plays an oncogenic role in cervical cancer cell proliferation by directly targeting p21, and thus promoting cell cycle progression. Therefore, these findings suggest that miR-92a can constitute a useful therapeutic target for cervical cancer. Wang et al. [65], demonstrated that the overexpression of miR-31 was associated with poor prognosis and aggressive phenotype of cervical cancer. These authors also implied that miR-31 plays an important role in the regulation of cervical cancer's malignant behavior, including cell proliferation and invasion, by directly targeting ARID1A. In general, miR-31 provides new insights into prognostic diagnosis and therapeutic strategies for patients with cervical cancer.

Multiple miRNAs have been identified by regulating different genes from a regulatory axis between long and circular non-coding RNAs, miRNAs, and target genes [43,45,52]. For example, functional assays have shown that inhibition of SNHG12 expression decreased cell proliferation both in vitro and in vivo, indicating that SNHG12 plays a critical role in the progression of cervical cancer [81]. MiR-424-5p was downregulated in cervical cancer tissues, and in addition, there was a negative correlation between SNHG12 and the expression of miR-424-5p in cervical cancer tissues [81]. The silencing of miR-424-5p in CC cells with SNHG12 depletion reversed the effects on apoptosis, migration, and cell invasion induced by the SNHG12 knockdown. Another study [80], showed that TTN-AS1 positively modulates E2F3 expression by regulating miR-573 in CC cells. These data revealed that the TTN-AS1 lncRNA was involved in the progression of CC cells by regulating the miR573-E2F3 axis. Ding and Zhang [43] demonstrated that the circular RNA circ-ATP8A2 promoted the progression of CC cells regulating the signaling of the miR-433/EGFR axis.

Currently, treatment for metastatic or recurrent CC is still a challenge, since the overall prognosis for this disease in advanced stages remains poor. Bearing in mind that some miRNAs are regulators of tumorigenesis in some types of cancer, and therefore represent powerful therapeutic targets. Thus, the incorporation of new therapeutic targets could be more effective for the treatment of this advanced CC. Coeh et al. [13] described new immunotherapeutic approaches that may demonstrate promising results in the future. In this sense, several target therapies have been explored; an example of this is the BEATcc study (NCT03556839), which is a randomized phase 3 study that uses standard platinumbased chemotherapy plus paclitaxel with bevacizumab versus the ligand-programmed cell death inhibitor 1 (PD-L1) atezolizumab compared to platinum chemotherapy plus paclitaxel and bevacizumab in metastatic, persistent, or recurrent CC. To date, the study is still in the recruitment of patients, and the test is expected to close in the third quarter of 2022, and it is hoped that mature BEATcc test data can be reported by 2023 [82].

Forterre et al. [83] highlighted that although the role of miRNA as a regulator of several physiological processes is evident, the main challenge today is in delivering tissuespecific molecules to the cells of interest. Therefore, several approaches have been studied in both in vitro and in vivo assays, in order to evaluate the best methodology for delivering miRNA in tumors for therapeutic purposes. In this sense, CC has many advantages for miRNA therapeutic delivery when compared with other tumors. Since local administration is limited to accessible tumors, as is the case with CC, the benefits of this therapy can be quite interesting, as the intratumoral injection toxicity of mimetizers or miRNA inhibitors is significantly greater than for those treatments administered by systemic routes [83]. Hanna et al. demonstrated in a review stating that there are studies prior to phase 3 to investigate new drug candidates for miRNA drugs, although there is still no phase 3 study registered in the clinictrials.gov database [84]. 
Another advantage of miRNAs is the potential to be used as biomarkers for accurate diagnosis, targeted treatment, and prediction of response to treatment. This is especially important in CC, a totally heterogeneous disease, in which a multi-marker approach would be preferable [85]. In this context, Xiong et al. [86] identified a multi-marker panel of nine miRNAs for breast carcinoma that has been shown to significantly improve the reliability of the diagnosis of breast cancer. However, for CC there are still no studies that include multi-marker miRNAs. However, research on miRNAs as biomarkers is still in its early stages, so at the moment, the findings generally lack reproducibility.

Among the five hallmarks of cancer [76] identified in this study (Figure 5), the hallmark that showed the most DEmiRNAs was sustained proliferative signaling, with 18 downregulated tsmiRs and six upregulated oncomiRs in patients with CC. Among the different miRNAs identified in this pathway, Ou et al. [49] found that miR-132 can play an important role in regulating the progression of cervical cancer, contributing to the growth and progression of cervical cancer through the depression of the expression of the RDX oncogene as underlying mechanism. On the other hand, it was seen that miR-411 inhibited the progression of cervical cancer when interacting directly with STAT3; the authors also indicated that this miRNA may represent a new potential therapeutic target and prognostic marker for patients with this disease [50]. The enabling replicative immortality marker showed the least miRNAs that regulate genes associated with this pathway. All identified genes that result in promoting replicative immortality are associated with the cell cycle, allowing the cell to migrate early from phase G1 to phase S, as is the case with the CDKN1A [55] and p21 [63] genes that are downregulated by miRNAs miR-93 [55] and miR-92a [63], respectively. Other miRNAs have also been identified in the pathways of evading growth suppressors, activation of invasion and metastasis, and resisting cell death. According to Zhou et al. [64], the interaction axis between miR-195 and Smad3 provides an insight into cervical cancer metastasis and may represent a novel therapeutic target. For this reason, we highlight the importance of identifying pathway regulating miRNAs responsible for the progression of cervical cancer so that potential biomarkers can be identified as future therapeutic targets.

\section{Conclusions}

In conclusion, the evidence highlighted in the present study showed that miRNAs affect various biological pathways associated with cancer development and progression, and clinical outcome and treatment response in CC, reinforcing their roles as key players in carcinogenesis. Consequently, their use in cervical cancer for clinical outcome prediction and therapy improvement may be valuable, facilitating disease classification, monitoring of the progression of cervical cancer, and therapeutic use for patients with resistant treatment disease.

Author Contributions: R.L.C. developed and led the overall study, conducted the data reviews and the analysis, and was involved in draft preparation. A.J.A.d.F. conducted the data reviews and the analysis, and critically read the manuscript. C.M.T.H.F. participated in preparing the manuscript and critically read the manuscript. R.d.R. participated in designing and developing the study, and critically read the manuscript. R.M.R. participated in designing and developing the study, and critically read the manuscript. M.M.C.M. conceived the study, provided advice during the study's development, and prepared the manuscript. All authors have read and agreed to the published version of the manuscript.

Funding: This research was funded by São Paulo Research Foundation (FAPESP) (grant \#2016/15831-3) and the present study was partially supported by PRONON "Identificação de biomarcadores para screening $e$ deteção precoce de tumores no contexto do Sistema Único de Saúde (SUS)." RMR is recipient of a CNPq Productivity fellowship.

Data Availability Statement: No new data were created or analyzed in this study. Data sharing is not applicable to this article. 
Acknowledgments: The authors would like to thank to events sector, especially Caio Fernando de Oliveira. In addition, we would like to thank the sources of funding: FAPESP, grant number 2016/15831-3, the Research Incentive Program of Barretos Cancer Hospital (PAIP), and PRONON. Additionally, Rui Manuel Reis was the recipient of a National Council of Technological and Scientific Development (CNPq) scholarship.

Conflicts of Interest: The authors declare that the research was conducted in the absence of any commercial or financial relationships that could be construed as potential conflicts of interest.

\section{References}

1. Crosbie, E.J.; Einstein, M.H.; Franceschi, S.; Kitchener, H.C. Human Papillomavirus and Cervical Cancer. Lancet 2013, 382, 889-899. [CrossRef]

2. Rosa, M.I.d.; Medeiros, L.R.; Rosa, D.D.; Bozzeti, M.C.; Silva, F.R.; Silva, B.R. Human Papillomavirus and Cervical Neoplasia. Cadernos Saúde Púb. 2009, 25, 953-964. [CrossRef]

3. Ferlay, J.; Colombet, M.; Soerjomataram, I.; Mathers, C.; Parkin, D.M.; Piñeros, M.; Znaor, A.; Bray, F. Estimating the Global Cancer Incidence and Mortality in 2018: GLOBOCAN Sources and Methods. Int. J. Cancer 2018. [CrossRef] [PubMed]

4. Ferlay, J.; Shin, H.-R.; Bray, F.; Forman, D.; Mathers, C.; Parkin, D.M. Estimates of Worldwide Burden of Cancer in 2008: GLOBOCAN 2008. Int. J. Cancer 2010, 127, 2893-2917. [CrossRef] [PubMed]

5. INCA-Instituto Nacional de Câncer-Estimativa 2018. Available online: http://www1.inca.gov.br/estimativa/2018/ (accessed on 18 November 2019).

6. Parkin, D.M.; Bray, F. The Burden of HPV-Related Cancers. Vaccine 2006, 24, S11-S25. [CrossRef]

7. Sepúlveda, C.; Prado, R. Effective Cervical Cytology Screening Programmes in Middle-Income Countries: The Chilean Experience. Cancer Detection Prevention 2005, 29, 405-411. [CrossRef] [PubMed]

8. Hull, R.; Mbele, M.; Makhafola, T.; Hicks, C.; Wang, S.-M.; Reis, R.M.; Mehrotra, R.; Mkhize-Kwitshana, Z.; Kibiki, G.; Bates, D.O.; et al. Cervical Cancer in Low and Middle-income Countries (Review). Oncol. Letters 2020, 20, 2058-2074. [CrossRef]

9. Arbyn, M.; Weiderpass, E.; Bruni, L.; de Sanjosé, S.; Saraiya, M.; Ferlay, J.; Bray, F. Estimates of Incidence and Mortality of Cervical Cancer in 2018: A Worldwide Analysis. Lancet Global Health 2020, 8, e191-e203. [CrossRef]

10. Zhao, Y.-B.; Wang, J.-H.; Chen, X.-X.; Wu, Y.-Z.; Wu, Q. Values of Three Different Preoperative Regimens in Comprehensive Treatment for Young Patients with Stage Ib2 Cervical Cancer. Asian Pac. J. Cancer Prev. 2012, 13, 1487-1489. [CrossRef]

11. Burki, T.K. Cervical Cancer: Screening and Risk with Age. Lancet Oncol. 2014, 15, e107. [CrossRef]

12. Naga Ch, P.; Gurram, L.; Chopra, S.; Mahantshetty, U. The Management of Locally Advanced Cervical Cancer. Curr. Opin. Oncol. 2018. [CrossRef]

13. Cohen, P.A.; Jhingran, A.; Oaknin, A.; Denny, L. Cervical Cancer. Lancet 2019, 393, 169-182. [CrossRef]

14. Green, J.A.; Kirwan, J.M.; Tierney, J.F.; Symonds, P.; Fresco, L.; Collingwood, M.; Williams, C.J. Survival and Recurrence after Concomitant Chemotherapy and Radiotherapy for Cancer of the Uterine Cervix: A Systematic Review and Meta-Analysis. Lancet 2001, 358, 781-786. [CrossRef]

15. De Castro, I. Análise da Expressão de Micrornas em Murganhos Transgénicos K14-HPV16: Implicações na Carcinogénesis. Master's Thesis, University of Porto, Porto, Portugal, September 2011.

16. Burd, E.M. Human Papillomavirus and Cervical Cancer. Clin. Microbiol. Rev. 2003, 16, 1-17. [CrossRef] [PubMed]

17. Cooper, D.B.; McCathran, C.E. Cervical, Dysplasia. In StatPearls; StatPearls Publishing: Treasure Island, FL, USA, 2017.

18. Smalley Rumfield, C.; Roller, N.; Pellom, S.T.; Schlom, J.; Jochems, C. Therapeutic Vaccines for HPV-Associated Malignancies. Immunotargets Ther. 2020, 9, 167-200. [CrossRef] [PubMed]

19. Wentzensen, N.; Vinokurova, S.; von Knebel Doeberitz, M. Systematic Review of Genomic Integration Sites of Human Papillomavirus Genomes in Epithelial Dysplasia and Invasive Cancer of the Female Lower Genital Tract. Cancer Res. 2004, 64, 3878-3884. [CrossRef] [PubMed]

20. Rosa, M.N.; Evangelista, A.F.; Leal, L.F.; De Oliveira, C.M.; Silva, V.A.O.; Munari, C.C.; Munari, F.F.; Matsushita, G.D.M.; Dos Reis, R.; Andrade, C.E.; et al. Establishment, Molecular and Biological Characterization of HCB-514: A Novel Human Cervical Cancer Cell Line. Sci. Rep. 2019, 9, 1913. [CrossRef]

21. Calin, G.A.; Sevignani, C.; Dumitru, C.D.; Hyslop, T.; Noch, E.; Yendamuri, S.; Shimizu, M.; Rattan, S.; Bullrich, F.; Negrini, M.; et al. Human MicroRNA Genes Are Frequently Located at Fragile Sites and Genomic Regions Involved in Cancers. Proc. Natl. Acad. Sci. USA 2004, 101, 2999-3004. [CrossRef]

22. He, L.; Hannon, G.J. MicroRNAs: Small RNAs with a Big Role in Gene Regulation. Nat. Rev. Genet. 2004, 5, 522-531. [CrossRef]

23. Ferracin, M.; Negrini, M. Micromarkers 2.0: An Update on the Role of MicroRNAs in Cancer Diagnosis and Prognosis. Expert Rev. Mol. Diagn. 2015, 15, 1369-1381. [CrossRef]

24. Iorio, M.V.; Croce, C.M. Causes and Consequences of MicroRNA Dysregulation. Cancer J. 2012, 18, 215-222. [CrossRef]

25. He, Y.; Lin, J.; Ding, Y.; Liu, G.; Luo, Y.; Huang, M.; Xu, C.; Kim, T.K.; Etheridge, A.; Lin, M.; et al. A Systematic Study on Dysregulated MicroRNAs in Cervical Cancer Development. Int. J. Cancer 2016, 138, 1312-1327. [CrossRef]

26. Almeida, M.I.; Reis, R.M.; Calin, G.A. MicroRNA History: Discovery, Recent Applications, and next Frontiers. Mutat. Res. 2011, 717, 1-8. [CrossRef] [PubMed]

27. Ha, M.; Kim, V.N. Regulation of MicroRNA Biogenesis. Nat. Rev. Mol. Cell Biol. 2014, 15, 509-524. [CrossRef] [PubMed] 
28. Lin, S.; Gregory, R.I. MicroRNA Biogenesis Pathways in Cancer. Nat. Rev. Cancer 2015, 15, 321-333. [CrossRef] [PubMed]

29. Pal, A.; Kundu, R. Human Papillomavirus E6 and E7: The Cervical Cancer Hallmarks and Targets for Therapy. Front Microbiol. 2020, 10. [CrossRef] [PubMed]

30. Razavi, Z.S.; Tajiknia, V.; Majidi, S.; Ghandali, M.; Mirzaei, H.R.; Rahimian, N.; Hamblin, M.R.; Mirzaei, H. Gynecologic Cancers and Non-Coding RNAs: Epigenetic Regulators with Emerging Roles. Crit. Rev. Oncol. Hematol. 2021, 157, 103192. [CrossRef] [PubMed]

31. Kumar, M.S.; Lu, J.; Mercer, K.L.; Golub, T.R.; Jacks, T. Impaired MicroRNA Processing Enhances Cellular Transformation and Tumorigenesis. Nat. Genet. 2007, 39, 673-677. [CrossRef] [PubMed]

32. Grzywa, T.M.; Klicka, K.; Włodarski, P.K. Regulators at Every Step-How MicroRNAs Drive Tumor Cell Invasiveness and Metastasis. Cancers 2020, 12, 3709. [CrossRef]

33. Svoronos, A.A.; Engelman, D.M.; Slack, F.J. OncomiR or Tumor Suppressor? The Duplicity of MicroRNAs in Cancer. Cancer Res. 2016, 76, 3666-3670. [CrossRef]

34. Zheng, T.; Wang, J.; Chen, X.; Liu, L. Role of MicroRNA in Anticancer Drug Resistance. Int. J. Cancer 2010, 126, 2-10. [CrossRef]

35. Parasramka, M.A.; Ho, E.; Williams, D.E.; Dashwood, R.H. MicroRNAs, Diet, and Cancer: New Mechanistic Insights on the Epigenetic Actions of Phytochemicals. Mol. Carcinogenesis 2012, 51, 213-230. [CrossRef]

36. Kota, S.K.; Balasubramanian, S. Cancer Therapy via Modulation of Micro RNA Levels: A Promising Future. Drug Discovery Today 2010, 15, 733-740. [CrossRef]

37. Hayes, J.; Peruzzi, P.P.; Lawler, S. MicroRNAs in Cancer: Biomarkers, Functions and Therapy. Trends Mol. Med. 2014, 20, 460-469. [CrossRef]

38. Liberati, A.; Altman, D.G.; Tetzlaff, J.; Mulrow, C.; Gøtzsche, P.C.; Ioannidis, J.P.A.; Clarke, M.; Devereaux, P.J.; Kleijnen, J.; Moher, D. The PRISMA Statement for Reporting Systematic Reviews and Meta-Analyses of Studies That Evaluate Health Care Interventions: Explanation and Elaboration. PLoS Med. 2009, 6, e1000100. [CrossRef]

39. Moher, D.; Liberati, A.; Tetzlaff, J.; Altman, D.G.; Group, T.P. Preferred Reporting Items for Systematic Reviews and Meta-Analyses: The PRISMA Statement. PLoS Med. 2009, 6, e1000097. [CrossRef] [PubMed]

40. Methley, A.M.; Campbell, S.; Chew-Graham, C.; McNally, R.; Cheraghi-Sohi, S. PICO, PICOS and SPIDER: A Comparison Study of Specificity and Sensitivity in Three Search Tools for Qualitative Systematic Reviews. BMC Health Serv. Res. 2014, 14. [CrossRef] [PubMed]

41. Chen, J.; Li, G. MiR-1284 Enhances Sensitivity of Cervical Cancer Cells to Cisplatin via Downregulating HMGB1. Biomed. Pharmacother. 2018, 107, 997-1003. [CrossRef] [PubMed]

42. Chen, Y.; Ma, C.; Zhang, W.; Chen, Z.; Ma, L. Down Regulation of MiR-143 Is Related with Tumor Size, Lymph Node Metastasis and HPV16 Infection in Cervical Squamous Cancer. Diagn. Pathol. 2014, 9, 88. [CrossRef] [PubMed]

43. Ding, L.; Zhang, H. Circ-ATP8A2 Promotes Cell Proliferation and Invasion as a CeRNA to Target EGFR by Sponging MiR-433 in Cervical Cancer. Gene 2019, 705, 103-108. [CrossRef] [PubMed]

44. Dong, J.; Wang, Q.; Li, L.; Xiao-Jin, Z. Upregulation of Long Non-Coding RNA Small Nucleolar RNA Host Gene 12 Contributes to Cell Growth and Invasion in Cervical Cancer by Acting as a Sponge for MiR-424-5p. Cell. Physiol. Biochem. 2018, 45, 2086-2094. [CrossRef] [PubMed]

45. Gao, F.; Feng, J.; Yao, H.; Li, Y.; Xi, J.; Yang, J. LncRNA SBF2-AS1 Promotes the Progression of Cervical Cancer by Regulating MiR-361-5p/FOXM1 Axis. Artif Cells Nanomed. Biotechnol. 2019, 47, 776-782. [CrossRef] [PubMed]

46. Hu, Y.; Ma, Y.; Liu, J.; Cai, Y.; Zhang, M.; Fang, X. LINC01128 Expedites Cervical Cancer Progression by Regulating MiR-3835p/SFN Axis. BMC Cancer 2019, 19. [CrossRef]

47. Liang, H.; Zhang, C.; Guan, H.; Liu, J.; Cui, Y. LncRNA DANCR Promotes Cervical Cancer Progression by Upregulating ROCK1 via Sponging MiR-335-5p. J. Cell. Physiol. 2019, 234, 7266-7278. [CrossRef]

48. Liao, H.; Pan, Y.; Pan, Y.; Shen, J.; Qi, Q.; Zhong, L.; Han, W.; Wang, Q.; Jiang, Y. MicroRNA-874 Is Downregulated in Cervical Cancer and Inhibits Cancer Progression by Directly Targeting ETS1. Oncol. Rep. 2018, 40, 2389-2398. [CrossRef]

49. Ou, R.; Zhu, L.; Zhao, L.; Li, W.; Tao, F.; Lu, Y.; He, Q.; Li, J.; Ren, Y.; Xu, Y. HPV16 E7-Induced Upregulation of KDM2A Promotes Cervical Cancer Progression by Regulating MiR-132-Radixin Pathway. J. Cell. Physiol. 2019, 234, 2659-2671. [CrossRef]

50. Shan, D.; Shang, Y.; Hu, T. MicroRNA-411 Inhibits Cervical Cancer Progression by Directly Targeting STAT3. Oncol. Res. 2019, 27, 349-358. [CrossRef]

51. Shao, S.; Wang, C.; Wang, S.; Zhang, H.; Zhang, Y. LncRNA STXBP5-AS1 Suppressed Cervical Cancer Progression via Targeting MiR-96-5p/PTEN Axis. Biomed. Pharmacother. 2019, 117, 109082. [CrossRef]

52. Wang, Y.; Wang, L.; Wang, W.; Guo, X. Overexpression of Circular RNA Hsa_circ_0001038 Promotes Cervical Cancer Cell Progression by Acting as a CeRNA for MiR-337-3p to Regulate Cyclin-M3 and Metastasis-Associated in Colon Cancer 1 Expression. Gene 2020, 733, 144273. [CrossRef]

53. Xu, L.-J.; Duan, Y.; Wang, P.; Yin, H.-Q. MiR-199b-5p Promotes Tumor Growth and Metastasis in Cervical Cancer by downRegulating KLK10. Biochem. Biophys. Res. Commun. 2018, 503, 556-563. [CrossRef]

54. Xu, Y.; Zhou, W.; Zhang, C.; Liu, X.; Lv, J.; Li, X.; Zhao, L.; Li, W.; Li, J.; Ren, Y.; et al. Long Non-Coding RNA RP11-552M11.4 Favors Tumorigenesis and Development of Cervical Cancer via Modulating MiR-3941/ATF1 Signaling. Int. J. Biol. Macromol. 2019, 130, 24-33. [CrossRef] 
55. Zhang, X.; Li, F.; Zhu, L. Clinical Significance and Functions of MicroRNA-93/CDKN1A Axis in Human Cervical Cancer. Life Sci. 2018, 209, 242-248. [CrossRef]

56. Hu, C.; Wang, Y.; Li, A.; Zhang, J.; Xue, F.; Zhu, L. Overexpressed Circ_0067934 Acts as an Oncogene to Facilitate Cervical Cancer Progression via the MiR-545/EIF3C Axis. J. Cell. Physiol. 2019, 234, 9225-9232. [CrossRef]

57. Zhu, H.; Zheng, T.; Yu, J.; Zhou, L.; Wang, L. LncRNA XIST Accelerates Cervical Cancer Progression via Upregulating Fus through Competitively Binding with MiR-200a. Biomed. Pharmacother. 2018, 105, 789-797. [CrossRef] [PubMed]

58. Liang, C.; Ding, J.; Yang, Y.; Deng, L.; Li, X. MicroRNA-433 Inhibits Cervical Cancer Progression by Directly Targeting Metadherin to Regulate the AKT and $\beta$-Catenin Signalling Pathways. Oncol. Rep. 2017, 38, 3639-3649. [CrossRef]

59. Dong, P.; Xiong, Y.; Hanley, S.J.B.; Yue, J.; Watari, H. Musashi-2, a Novel Oncoprotein Promoting Cervical Cancer Cell Growth and Invasion, Is Negatively Regulated by P53-Induced MiR-143 and MiR-107 Activation. J. Exp. Clin. Cancer Res. 2017, 36, 150. [CrossRef] [PubMed]

60. Hu, T.; Chang, Y.-F.; Xiao, Z.; Mao, R.; Tong, J.; Chen, B.; Liu, G.-C.; Hong, Y.; Chen, H.-L.; Kong, S.-Y.; et al. MiR-1 Inhibits Progression of High-Risk Papillomavirus-Associated Human Cervical Cancer by Targeting G6PD. Oncotarget 2016, 7, 86103-86116. [CrossRef] [PubMed]

61. Huang, P.; Xi, J.; Liu, S. MiR-139-3p Induces Cell Apoptosis and Inhibits Metastasis of Cervical Cancer by Targeting NOB1. Biomed. Pharmacother. 2016, 83, 850-856. [CrossRef] [PubMed]

62. Huang, Y.; Li, Y.; Wang, F.F.; Lv, W.; Xie, X.; Cheng, X. Over-Expressed MiR-224 Promotes the Progression of Cervical Cancer via Targeting RASSF8. PLoS ONE 2016, 11, e0162378. [CrossRef]

63. Su, Z.; Yang, H.; Zhao, M.; Wang, Y.; Deng, G.; Chen, R. MicroRNA-92a Promotes Cell Proliferation in Cervical Cancer via Inhibiting P21 Expression and Promoting Cell Cycle Progression. Oncol. Res. 2017, 25, 137-145. [CrossRef] [PubMed]

64. Zhou, Q.; Han, L.R.; Zhou, Y.X.; Li, Y. MiR-195 Suppresses Cervical Cancer Migration and Invasion Through Targeting Smad3. Int. J. Gynecol. Cancer 2016, 26, 817-824. [CrossRef] [PubMed]

65. Wang, N.; Zhou, Y.; Zheng, L.; Li, H. MiR-31 Is an Independent Prognostic Factor and Functions as an Oncomir in Cervical Cancer via Targeting ARID1A. Gynecol. Oncol. 2014, 134, 129-137. [CrossRef] [PubMed]

66. Xu, J.; Li, Y.; Wang, F.; Wang, X.; Cheng, B.; Ye, F.; Xie, X.; Zhou, C.; Lu, W. Suppressed MiR-424 Expression via Upregulation of Target Gene Chk1 Contributes to the Progression of Cervical Cancer. Oncogene 2013, 32, 976-987. [CrossRef]

67. Xu, J.; Wan, X.; Chen, X.; Fang, Y.; Cheng, X.; Xie, X.; Lu, W. MiR-2861 Acts as a Tumor Suppressor via Targeting EGFR/AKT2/CCND1 Pathway in Cervical Cancer Induced by Human Papillomavirus Virus 16 E6. Sci. Rep. 2016, 6, 28968. [CrossRef]

68. Hou, X.W.; Sun, X.; Yu, Y.; Zhao, H.M.; Yang, Z.J.; Wang, X.; Cao, X.C. MiR-361-5p Suppresses Lung Cancer Cell Lines Progression by Targeting FOXM1. Neoplasma 2017, 64, 526-534. [CrossRef] [PubMed]

69. Tian, L.; Zhao, Z.; Xie, L.; Zhu, J. MiR-361-5p Suppresses Chemoresistance of Gastric Cancer Cells by Targeting FOXM1 via the PI3K/Akt/MTOR Pathway. Oncotarget 2018, 9, 4886-4896. [CrossRef] [PubMed]

70. Zhang, Y.; Xu, Z. MiR-93 Enhances Cell Proliferation by Directly Targeting CDKN1A in Nasopharyngeal Carcinoma. Oncol. Letters 2018, 15, 1723-1727. [CrossRef]

71. He, Y.; Yu, B. MicroRNA-93 Promotes Cell Proliferation by Directly Targeting P21 in Osteosarcoma Cells. Exp. Ther. Med. 2017, 13, 2003-2011. [CrossRef]

72. Li, C.; Lyu, J.; Meng, Q.H. MiR-93 Promotes Tumorigenesis and Metastasis of Non-Small Cell Lung Cancer Cells by Activating the PI3K/Akt Pathway via Inhibition of LKB1/PTEN/CDKN1A. J. Cancer 2017, 8, 870-879. [CrossRef]

73. Ohta, K.; Hoshino, H.; Wang, J.; Ono, S.; Iida, Y.; Hata, K.; Huang, S.K.; Colquhoun, S.; Hoon, D.S.B. MicroRNA-93 Activates c-Met/PI3K/Akt Pathway Activity in Hepatocellular Carcinoma by Directly Inhibiting PTEN and CDKN1A. Oncotarget 2015, 6, 3211-3224. [CrossRef] [PubMed]

74. Wang, S.-J.; Cao, Y.-F.; Yang, Z.-Q.; Jiang, Z.-Y.; Cai, B.; Guo, J.; Zhang, S.; Zhang, X.-L.; Gao, F. MicroRNA-93-5p Increases Multidrug Resistance in Human Colorectal Carcinoma Cells by Downregulating Cyclin Dependent Kinase Inhibitor 1A Gene Expression. Oncol. Lett. 2017, 13, 722-730. [CrossRef] [PubMed]

75. Su, X.; Wang, H.; Ge, W.; Yang, M.; Hou, J.; Chen, T.; Li, N.; Cao, X. An In Vivo Method to Identify MicroRNA Targets Not Predicted by Computation Algorithms: P21 Targeting by MiR-92a in Cancer. Cancer Res. 2015, 75, 2875-2885. [CrossRef] [PubMed]

76. Hanahan, D.; Weinberg, R.A. Hallmarks of Cancer: The next Generation. Cell 2011, 144, 646-674. [CrossRef] [PubMed]

77. Creasman, W.T.; Odicino, F.; Maisonneuve, P.; Quinn, M.A.; Beller, U.; Benedet, J.L.; Heintz, A.P.M.; Ngan, H.Y.S.; Pecorelli, S. Carcinoma of the Corpus Uteri. FIGO 26th Annual Report on the Results of Treatment in Gynecological Cancer. Int. J. Gynaecol. Obstet 2006, 95 Suppl 1, S105-S143. [CrossRef]

78. Kong, Y.W.; Ferland-McCollough, D.; Jackson, T.J.; Bushell, M. MicroRNAs in Cancer Management. Lancet Oncol. 2012, 13, e249-e258. [CrossRef]

79. González-Quintana, V.; Palma-Berré, L.; Campos-Parra, A.D.; López-Urrutia, E.; Peralta-Zaragoza, O.; Vazquez-Romo, R.; Pérez-Plasencia, C. MicroRNAs Are Involved in Cervical Cancer Development, Progression, Clinical Outcome and Improvement Treatment Response (Review). Oncol. Rep. 2016, 35, 3-12. [CrossRef]

80. Chen, P.; Wang, R.; Yue, Q.; Hao, M. Long Non-Coding RNA TTN-AS1 Promotes Cell Growth and Metastasis in Cervical Cancer via MiR-573/E2F3. Biochem. Biophys. Res. Commun. 2018, 503, 2956-2962. [CrossRef] 
81. Jin, X.-J.; Chen, X.-J.; Zhang, Z.-F.; Hu, W.-S.; Ou, R.-Y.; Li, S.; Xue, J.-S.; Chen, L.-L.; Hu, Y.; Zhu, H. Long Noncoding RNA SNHG12 Promotes the Progression of Cervical Cancer via Modulating MiR-125b/STAT3 Axis. J. Cell. Physiol. 2019, 234, 6624-6632. [CrossRef]

82. Grau, J.F.; Farinas-Madrid, L.; Oaknin, A. A Randomized Phase III Trial of Platinum Chemotherapy plus Paclitaxel with Bevacizumab and Atezolizumab versus Platinum Chemotherapy plus Paclitaxel and Bevacizumab in Metastatic (Stage IVB), Persistent, or Recurrent Carcinoma of the Cervix: The BEATcc Study (ENGOT-Cx10/GEICO 68-C/JGOG1084/GOG-3030). Int. J. Gynecol. Cancer 2020, 30, 139-143. [CrossRef] [PubMed]

83. Forterre, A.; Komuro, H.; Aminova, S.; Harada, M. A Comprehensive Review of Cancer MicroRNA Therapeutic Delivery Strategies. Cancers 2020, 12, 1852. [CrossRef] [PubMed]

84. Hanna, J.; Hossain, G.S.; Kocerha, J. The Potential for MicroRNA Therapeutics and Clinical Research. Front Genet. 2019, 10, 478. [CrossRef] [PubMed]

85. Condrat, C.E.; Thompson, D.C.; Barbu, M.G.; Bugnar, O.L.; Boboc, A.; Cretoiu, D.; Suciu, N.; Cretoiu, S.M.; Voinea, S.C. MiRNAs as Biomarkers in Disease: Latest Findings Regarding Their Role in Diagnosis and Prognosis. Cells 2020, 9, 276. [CrossRef] [PubMed]

86. Xiong, D.-D.; Lv, J.; Wei, K.-L.; Feng, Z.-B.; Chen, J.-T.; Liu, K.-C.; Chen, G.; Luo, D.-Z. A Nine-MiRNA Signature as a Potential Diagnostic Marker for Breast Carcinoma: An Integrated Study of 1,110 Cases. Oncol. Rep. 2017, 37, 3297-3304. [CrossRef] 